\title{
Peningkatan Kualitas Hidup Orang Dengan Gangguan Jiwa Melalui Self Help Group
}

\author{
Endang Caturini Sulistyowati ${ }^{1 *}$, Insiyah $^{2}$ \\ Jurusan Keperawatan, Poltekkes Kemenkes Surakarta \\ *Email : endangcaturini70@gmail.com
}

\begin{abstract}
Background: People who suffer from mental disorders experience various problems with different symptoms. Generally, they have characteristics with some combination of abnormal thoughts, emotions, behavior and relationships with other people. These characteristics can be manifested in the form of a series of symptoms and changes in behavior which is meaningful and can cause suffering and obstacles in carrying out people's functions as humans. This is a serious health problem, which usually has problems with poor quality of life. They are related with sentiments of trouble, absence of authority over manifestations and life all in all, negative impression of self, demonization and dismissal, decreased movement and trouble with every day working, and negative standpoint. Group interventions carried out by nurses such as group activity therapy, supportive therapy and self-help groups to help individuals improvement in their quality of life. Group therapy, one of the self help group, is a group where each member has similar longing to conquer mental issues or increment the degree of psychological or passionate prosperity among bunch individual. Self Help group intends to create empathy among individuals in groups where they give common fortification which affects improving the personal satisfaction.This study aims to determine the improvement of the quality of life of people with mental disorders (ODGJ) using the self help group in the city of Surakarta. Methods: This was a quasiexperimental study with a pre-post test control group design. Information were taken when giving the intervention of self improvement gatherings of schizophrenia patients in the intercession gathering. The number of respondents was 160 people, where the control group was given treatment as usual from the hospital while the intervention group was given a self-help group intervention. This study measures the quality of life with a research instrument using a life quality questionnaire. Data were analyzed using independent t-test and Mann Whitney-test. Results: The investigation demonstrated that there was a factually critical contrast in the personal satisfaction when giving the self help group ( $p$ value, 0.000) between the intervention group and the control group, both at Griya PMI with a mean distinction of 20.23 and at RSJD Dr. Arif Z. Self help group with a mean distinction of 10.85. Conclusion: self help group which is used for intervention is considered effective to improve quality of life. Implication: self help group is one of the interventions that can be provided as an additional intervention in the hospital because these interventions have a better impact on improving the quality of life for people with mental disorders.
\end{abstract}

Keywords: odgj, quality of life, self help groups

\section{PENDAHULUAN}

Jumlah pasien gangguan jiwa di Indonesia dari waktu ke waktu mengalami peningkatan. Menurut Depkes RI (2018) prevalensi gangguan jiwa di Indonesia mencapai sebanyak 7,0 per 1.000 penduduk. Angka ini lebih banyak dibandingkan pada tahun 2013, prevalensi gangguan jiwa berat, seperti skizofrenia mencapai sekitar 400.000 orang atau sebanyak 1,7 per 1.000 penduduk
(Riskesdas, 2013). Sedangkan prevalensi gangguan jiwa skizofrenia di Jawa Tengah berdasarkan hasil Riskesdas tahun 2013 adalah 2.3 per 1000 penduduk, menempati peringkat ketiga secara nasional (Depkes RI 2013). Angka ini meningkat menjadi 9 per 1000 penduduk dan menempati peringkat kelima secara nasional (Depkes RI 2018).

Orang yang mengalami gangguan jiwa pada umumnya memiliki 
karakteristik dengan beberapa kombinasi pemikiran abnormal, emosi, perilaku dan hubungan dengan orang lain yang bermanifestasi dalam bentuk sekumpulan gejala dan atau perubahan perilaku yang bermakna serta dapat menimbulkan penderitaan dan hambatan dalam menjalankan fungsi sebagai manusia (UU Kesehatan no 18 2014). Hal ini merupakan salah satu masalah kesehatan yang serius, yang biasanya berdampak terhadap kualitas hidup yang buruk.

Kualitas hidup berhubungan dengan situasi kehidupan sehari-hari individu. Kualitas hidup yang buruk sering dikaitkan dengan perasaan tertekan, kurangnya kontrol atas gejala dan kehidupan secara umum. Masalah individu yang dikaitkan dengan kualitas hidup antara lain: persepsi negatif tentang diri, stigmatisasi dan penolakan, berkurangnya aktivitas dan kesulitan dengan fungsi sehari-hari, serta pandangan negatif pada diri sendiri. Sebaliknya, kualitas hidup yang baik ditandai oleh perasaan kesejahteraan, kontrol dan otonomi, persepsi diri yang positif, rasa memiliki, partisipasi dalam kegiatan yang menyenangkan dan bermakna, dan pandangan positif tentang masa depan. Domain kehidupan ini berinteraksi dengan cara yang kompleks dan timbal balik (Connell, J, Brazier, J, O'Cathain, A, Jones, M.L. \& Paisley, S., 2012).

Berbagai macam intervensi dilakukan oleh perawat dari yang bersifat individu sampai terapi kelompok. Intervensi kelompok yang dilakukan perawat antara lain: terapi aktifitas kelompok, terapi suportif dan self help group. Self help group adalah intervensi kelompok dimana tiap anggota saling memiliki keinginan yang sama untuk meningkatkan derajat kesejahteraan psikologis atau antusiasme diantara sekelompok individu (Sulistyowati, E.C. and Sulistyowati D, 2019).

Metode yang digunakan dengan cara menyelesaikan masalah, self help group mengharapkan terciptanya welas asih diantara individu yang berkumpul dimana individu yang berkumpul memberikan dukungan bersama yang berdampak pada peningkatan kepuasan pribadi dan peningkatkan kualitas hidup.

Penelitian ini menggunakan Self Help Group yang dilakukan pada Orang Dengan Gangguan Jiwa (ODGJ) untuk peningkatan kualitas hidup. Hal ini berbeda dengan penelitian sebelumnya sebagai responden mengikutsertakan lansia dan keluarga, demikian juga berbeda pada variabel dependen dengan menggunakan mekanisme koping dan kemandirian.

\section{METODE PENELITIAN}

Metode dalam penelitian ini menggunakan quasi experiment pre-post test with control group, sebagai tindakan berupa Self Help Group (SHG) pada bulan Agustus sampai Oktober 2020. Sampel penelitian ini adalah ODGJ, berjumlah 160 orang yang diambil dengan metode purposive sampling.

Setiap kelompok berjumlah 80 orang untuk kelompok 1 di Griya PMI dan 80 untuk kelompok 2 di RSJD Dr Arif Z Surakarta, masing-masing kelompok terdiri 40 responden perlakuan dan 40 responden untuk kelompok kontrol. Kelompok perlakuan mendapat Self Help Group sebanyak 4 pertemuan (4 sesi) dalam rentang waktu 8 hari, dilakukan setelah pengukuran awal kualitas hidup, sedangkan kelompok kontrol tidak mendapatkan perlakuan 


\section{Self Help Group.}

Pengolahan data kualitas hidup sebelum dan setelah tindakan, dan diukur dengan mengunakan kusioner kualitas hidup (WHOQOL BREF, 2020) serta dianalisis dengan independent t-test dan mann whitney-test. Penelitian ini telah mendapatkan ethical clearance, dari Komisi Etik Penelitian Kesehatan Dr Moewardi Surakarta dengan nomer 979/VII/HREC/2020, tertanggal 19 Agustus 2020.

\section{HASIL PENELITIAN}

Hasil analisis penelitian menunjukkan bahwa dari 160 pasien usia rata-rata adalah 37,86 tahun dengan rentang usia 18 tahun sampai 56 tahun. Untuk rerata lamanya menderita selama 4,48 dengan lamanya menderita yang terendah 1 tahun dan terlama 16 tahun. Rerata frekuensi perawatan sebanyak 3,74 kali dengan jumlah perawatan yang minimal 1 kali dan maksimal 20 kali.

Hasil analisis terhadap proporsi pasien yang berjenis kelamin laki-laki 64\% (104) lebih banyak dari perempuan $35 \%$ (56). Pada pendidikan, yang terbanyak pasien berpendidikan SD 31,9\% (51) orang sedangkan SLTP 29,4\% (47) orang dan SMU 26,3\% (42) orang. Proporsi pasien sebelum sakit yang tidak bekerja 69,4\% (111)lebih banyak dari pada yang bekerja sebanyak 30,6\% (49). Proporsi pasien yang berstatus tidak kawin $61,9 \%$ (99) lebih banyak dari yang kawin $23,8 \%$ (38) atau janda/duda 6,3\% (10) dan cerai $8,1 \%(31)$.

Tabel 1. Hasil Uji Independen T-Test Tentang Perbedaan Kualitas Hidup Pada Kelompok Perlakuan dengan Kontrol, Setelah Tindakan SHG di Griya PMI Surakarta, Tahun $2020(\mathrm{n}=80)$.

\begin{tabular}{lccccc}
\hline Kelompok & $\mathbf{n}$ & Mean & SD & T & P \\
\hline Kontrol & 40 & 0,9 & 7,207 & $-8,028$ & 0,000 \\
Intervensi & 40 & 20,23 & 13,412 & & \\
Selisih & 80 & 19,33 & & & \\
\hline \multicolumn{5}{c}{ Hasil analisis pada tabel 1 dengan } & dengan selisih rerata 19,33. Rerata \\
uji independen t-test memperlihatkan & peningkatan kualitas hidup pasien pada \\
perbedaan secara statistik signifikan (p< & kelompok perlakuan (rerata 20,23) lebih \\
0,05.), mengenai kualiatas hidup ODGJ & tinggi dari pada kelompok kontrol (rerata \\
pada kelompok perlakuan dan kontrol & 0,9) dengan p =0,000
\end{tabular}

Tabel 2. Hasil Uji Mann-Whitney Test Perbedaan Perubahan Kualitas Hidup Antara Kelompok Kontrol dan Perlakuaan, Sesudah Tindakan SHG Di RSJD Dr Arif Z Surakarta, Tahun $2020(\mathrm{n}=80)$.

\begin{tabular}{lccllc}
\hline Kelompok & $\mathbf{n}$ & Mean & SD & $\mathbf{Z}$ & $\mathbf{P}$ \\
\hline Kontrol & 40 & 0,73 & 7,32 & $-7,608$ & 0,000 \\
Intervensi & 40 & 10,85 & 6,467 & & \\
Selisih & 80 & 10,12 & & & \\
\hline \multicolumn{1}{c}{ Hasil analisis } & pada tabel & 2 & 10,12 . Rerata peningkatan kualitas hidup \\
menggunakan uji mann-whitney test & $\begin{array}{l}\text { pasien pada kelompok perlakuan dengan } \\
\text { menunjukkan ada perbedaan }\end{array}$ yang & $\begin{array}{l}\text { rerata 10,85 lebih tinggi dari kelompok } \\
\text { signifikan (p <0.05) dengan selisih mean }\end{array}$ & kontrol rerata 0,73, dengan. p=0,00.
\end{tabular}


Tabel 3. Hasil Uji Mann-Whitney Test Tentang Perbedaan Perubahan Kualitas Hidup Antara Kelompok Intervensi dengan SHG dengan Kelompok Kontrol di Griya PMI Surakarta dan di RSJD Dr Arif Z Surakarta, Tahun 2020 ( $\mathrm{n}=160)$.

\begin{tabular}{lccccc}
\hline \multicolumn{1}{c}{ Kelompok } & n & Mean & SD & Z & P \\
\hline Kontrol & 80 & 0,09 & 7,264 & $-9,219$ & 0,000 \\
Intervensi & 80 & 15,54 & 11,476 & & \\
Selisih & 160 & 15,45 & & & \\
\hline
\end{tabular}

Hasil analisis menggunakan uji mannwhitney test menunjukan terdapat perbedaan yang signifikan $(\mathrm{p}<0,05)$, mengenai kualiatas hidup ODGJ antara kelompok intervensi dengan kelompok kontrol di Griya PMI Surakarta dan RSJD Dr Arif Z Surakarta, dengan selisih mean 15,45 . Rerata peningkatan kualitas hidup pada kelompok intervensi (mean 15,54) lebih tinggi dari pada kelompok kontrol (mean 0,09) dengan $p<0,000$.

\section{PEMBAHASAN}

Hasil penelitian menunjukan perbedaan peningkatan rerata kwalitas hidup sebesar 19,33, pada kelompok perlakuan setelah dilakukan SHG dengan rerata 20,23 lebiih tinggi dibandingkan dengan kelompok kontrol dengan rerata 0,9 di Griya PMI . Hasil ini sesuai juga dengan penelitian di RSJD Dr Arif Z bahwa terdapat perbedaan peningkatan mean sebesar 10,12, pada kelompok intervensi (mean 20,23) lebih tinggi dari pada kelompok kontrol (mean 0,9). Penelitian ini sejalan dengan penelitian sebelumnya, dimana perlakuan SHG meningkatkan kualiatas hidup sebesar rerata 11,7 sebelum dilakukan SHG dengan rerata 73,2 dan setelah dilakukan SHG sebesar 84,9 (Sudiantara., K dkk, 2015). Hal ini didukung Tew et al., (2012) bahwa suatu hubungan terutama dengan keluarga dan teman-teman, adalah pusat kualitas hidup. Peran penting untuk perawat kesehatan mental adalah untuk mendukung seseorang pulih dari penyakit

mental dalam pengembangan dan
pemeliharaan hubungan sosial yang positif.

Perubahan diperlukan dalam fokus perawatan kesehatan mental saat ini dari pendekatan individual, ke model perawatan yang lebih inklusif secara sosial yang mencakup keluarga, teman, dan komunitas dalam pemulihan individu (Barker \& Buchanan-Barker, 2011). Dalam hal ini SHG menjadi relevan dimana terapi ini untuk menumbuhkan simpati di antara individu yang berkumpul di mana individu yang berkumpul memberikan penguatan bersama, mengubah individu dalam sudut pandang mereka sendiri, mempelajari prosedur adaptasi baru, mempraktikkan perilaku (Sulistyowati, E.C. and Sulistyowati D, 2019).

Pendekatan perawatan kesehatan mental berdasarkan model sosial perawatan, yang menekankan pada pemberdayaan dan pengembangan kapasitas, dapat menawarkan cara baru untuk memahami kebutuhan kesehatan mental dan mempromosikan pemulihan (Heenan, 2006). Dukungan untuk kualitas hidup penting dilakukan secara berkelanjutan dan teratur; pasien diharapkan mampu mengidentifikasi akses terhadap ketersediaan dukungan yang teratur dan terus menerus sebagai prioritas utama dalam perawatan kesehatan mental mereka. Dukungan rutin dari perawat kesehatan jiwa merupakan elemen yang sangat penting dalam mempromosikan 
dan mempertahankan kualitas hidup yang positif. Berdasarkan temuan ini, sebaiknya Kesehatan jiwa disarankan menilai tingkat dukungan yang dibutuhkan pasien dan merencanakan tindakan keperawatan yang sesuai untuk memastikan dukungan memadai dan berkelanjutan. Pasien harus diberdayakan untuk mengidentifikasi elemen kehidupan mereka yang penting untuk menentukan kualitas hidupnya, untuk mengidentifikasi tujuan pribadi, dan memberikan wawasan tentang apa yang dapat dilakukan perawat untuk berkontribusi secara positif pada peningkatan kualitas hidup mereka (Williams et al., 2015).

Hasil penelitian sebelumnya menunjukkan bahwa kelompok memberikan kontribusi yang kuat bagi kesejahteraan mental anggota dengan meningkatkan rasa kendali, meningkat ketahanan dan memfasilitasi partisipasi. Anggota kelompok dapat bertukar dukungan emosional dan praktis; mereka mendapatkan harga diri, pengetahuan dan kepercayaan diri. Artikel tersebut memberikan basis bukti yang menggambarkan bagaimana selfhelp group dapat mengembangkan kemandirian atau hubungan timbal balik yang saling menguntungkan diantara kelompok mereka sendiri untuk meningkatkan rasa kesejahteraan mental. (Seebohm et al., 2013).

Self-help atau mutual aid groups adalah terkait dengan peningkatan harga diri dan kemampuan untuk mengatasinya, dan penurunan isolasi (Seebohm et al., 2013). Demikian juga Taylor (2011) setuju bahwa penekanan pada kemandirian individu terlalu sempit dan menjadi penting untuk mengenali sifat sosial manusia. Sementara Coote, Goodwin (2010) dan Marmot (2010) dalam Rowaert et al., (2018) membantah bahwa kebijakan kesejahteraan harus didasarkan pada sosial keadilan. Intervensi yang senada juga dilakukan oleh peneliti dan terhadap keluarga pasien yang disebut Family Support Group (FSG). FSG telah dikembangkan untuk mendukung anggota keluarga dalam menangani penyakit mental dan tatanan hukum kerabat mereka. Setelah FSG, anggota keluarga melaporkan lebih sedikit menyalahkan diri sendiri dan lebih sedikit beban (misalnya, penurunan kehilangan kontrol atas hidup mereka dan peningkatan kesejahteraan emosional). Faktor terapeutik seperti pembelajaran dengan observasi, modeling, dukungan dari kelompok, mengalami kesamaan dengan orang lain, dan universalitas masalah dikaitkan dengan hasil positif ini (Rowaert et al., 2018).

Hasil penelitian juga menunjukan perbedaan peningkatan Kualitas Hidup ODGJ antara kelompok intervensi setelah dilakukan SHG dengan kelompok kontrol di Griya PMI Surakarta dan RSJD Dr Arif $\mathrm{Z}$ Surakarta, dengan selisih mean 15,45 . Rerata peningkatan kualitas hidup pada kelompok intervensi (mean 15,54) lebih tinggi dari pada kelompok kontrol (mean 0,09). Banyak peserta menyampaikan tentang menghargai keterlibatan kelompok mereka dan itu merupakan peran yang berharga. Mereka ingin memberikan kembali bantuan yang mereka terima, untuk mencegah orang lain dalam kelompok memiliki keterbatasan dalam pengalaman klinis yang mereka miliki, atau untuk membantu komunitas mereka. Memberi sama pentingnya dengan menerima bantuan. Banyak anggota membantu dengan cara sederhana seperti pengorganisasian minuman atau berbagi pengalaman pribadi. Fasilitator 
menuntut secara mental dan emosional, tanggung jawab dan semangat untuk melakukan sesuatu yang membantu orang lain. Imbalan mereka adalah mengetahui bahwa mereka membuat perbedaan bagi kehidupan orang-orang lainnya melalui masukan dari anggota dan kesehatan mereka yang terlihat meningkat atau mendapatkan kebahagiaan (Seebohm et al., 2013).

Stigma diri telah dikaitkan dengan keputusasaan, miskin harga diri, penurunan pemberdayaan, penurunan kepatuhan pengobatan, dan peningkatan keparahan gejala (Livingston \& Boyd, 2010). Orang yang memiliki gangguan mental harus dirawat dalam pengaturan yang longgar, perawatan komunitas wajib memberikan strategi lain bagi mereka yang tidak membutuhkan rawat inap paksa tradisional, tetapi masih membutuhkan perawatan, pengawasan, dan dukungan. Meskipun stigma diri dirujuk secara luas sebagai hambatan substansial dalam proses pemulihan kesehatan mental, sifat pasti pengaruhnya terhadap kesehatan dan hasil sosial tetap tidak jelas. Sejauh mana stigma diri menyebabkan atau memperburuk hasil perawatan pada orang dengan gangguan mental, stigma diri memiliki implikasi penting bagi layanan dan kebijakan kesehatan mental. Misalnya, sejauh mana program dan intervensi kesehatan mental harus ditujukan dalam meningkatkan kualitas hidup orang dengan penyakit mental berkonsentrasi pada persepsi dan pengalaman stigma diri. Seiring waktu, stigma diri akan berdampak langsung pada pengikisan kualitas hidup di antara orang-orang dengan penyakit mental yang menerima perawatan komunitas wajib; Namun, hubungan ini tidak dikonfirmasi oleh data. Walaupun analisis cross- sectional mengungkapkan hubungan negatif yang sedang antara stigma diri dan kualitas hidup, analisis longitudinal menunjukkan bahwa stigma diri tidak dapat memprediksi kualitas hidup di antara peserta penelitian. Faktanya, setelah mengendalikan efek dari variabel perancu potensial, stigma diri dasar terhitung kurang dari satu persen dari variasi kualitas hidup 1 tahun kemudian (Livingston, 2012).

Aktivitas sosial bersama dapat berdampak positif terhadap kesehatan mental dan kesejahteraan, mempromosikan perkembangan persahabatan, dan mengurangi isolasi sosial (Hillier, 2007). Meskipun orang dengan penyakit mental yang parah menghadapi peningkatan risiko kematian dan kematian berdampak pada hasil kesehatan yang negatif, penelitian telah menunjukkan bahwa intervensi gaya hidup dapat mendukung kesehatan mereka. Penelitian oleh $\mathrm{Bj}$ and Haage (2018), meneliti intervensi gaya hidup yang dipimpin perawat untuk mengukur dampaknya terhadap kualitas kehidupan, kinerja kognitif, kapasitas berjalan, dan kesehatan tubuh orang dengan gangguan mental berat.

Hasil penelitian lain menunjukkan bahwa intervensi memberikan peningkatan signifikan dalam variabel kualitas hidup yang berhubungan dengan kesehatan, kinerja kognitif, kapasitas berjalan, dan lingkar pinggang untuk orang dengan gangguan mental, namun studi jangka panjang dengan kelompok kontrol dan yang memeriksa parameter hidup dengan gangguan kesehatan mental secara negatif mempengaruhi beberapa aspek kualitas hidup dengan mempromosikan kurangnya interaksi sosial, perasaan tertekan, dan kurangnya 
kontrol dan otonomi (Connell et al. 2012).

Hal inilah Self Help Group dapat meningkatkan kualitas hidup pasien, dimana dengan Self Help Group dalam kelompok pasien belajar bersama dan menemukan strategi pemecahan masalah baru yang didapatkan langsung dari pengalaman nyata. Pengalaman nyata ini bisa dirasakan pasien mengubah dalam perspektif diri mereka sendiri, sebagai latihan perilaku, penyesuaian dan proses pemulihan, sehingga dapat memperdayakan kemampuan dan kekuatannya untuk menggunakan kekuatan dan kemampuan dirinya mengambil peran dan tanggung jawabnya.

\section{KESIMPULAN DAN SARAN}

Hasil penelitian di Griya PMI terdapat perbedaan rerata sebesar 19,33 pada kelompok perlakuan rerata 20,23 dan kelompok kontrol rerata 0,9. Ada perbedaan peningkatan kualitas hidup yang signifikan ( $\mathrm{p}$ value $<\alpha 0,05$ ) antara kelompok perlakuaan dan kontrol, Demikian hasil penelitian di RSJD Dr Arif $\mathrm{Z}$ terdapat perbedaan peningkatan rerata sebesar 10,12, pada kelompok intervensi rerata 20,23 dan kelompok kontrol rerata 0,9. Self Help Group yang digunakan efektif untuk meningkatkan kualitas hidup.

Terdapat perbedaan secara statistik signifikan ( $\mathrm{p}$ value $<\alpha 0,05)$ Kualitas Hidup ODGJ antara kelompok intervensi setelah dilakukan SHG dengan kelompok kontrol di Griya PMI Surakarta dan RSJD Dr Arif Z Surakarta, dengan selisih mean 15,45 . Rerata peningkatan kualitas hidup pada kelompok intervensi (mean 15,54) lebih tinggi dari pada kelompok kontrol (mean 0,09).
Disarankan dalam pengelolaan pasien gangguan jiwa agar intervensi Self Help Group digunakan sebagai salah satu pedoman terapi kelompok dalam asuhan keperawatan jiwa.

\section{DAFTAR RUJUKAN}

Barker, P., \& Buchanan-Barker, P. (2011). Myth of mental health nursing and the challenge of recovery. International Journal of Mental Health Nursing, 20(5), 337-344. https://doi.org/10.1111/j.14470349.2010.00734.x

Bj, A., \& Haage, D. (2018). Educational nurse-led lifestyle intervention for persons with mental illness. 10221031. https://doi.org/10.1111/inm.12410

Connell, J., Brazier, J., O'Cathain, A., Lloyd-Jones, M., \& Paisley, S. (2012). Quality of life of people with mental health problems: A synthesis of qualitative research. Health and Quality of Life Outcomes, $10(1), \quad 1$. https://doi.org/10.1186/1477-7525$10-138$

Dep Kes RI. (2013). Riset Kesehatan Dasar. http://www.depkes.go.id/resources/ download/general/Hasil\%20Riskesd as\%202013.pdf

Dep Kes RI. (2018). Riset Kesehatan Dasar. http://www.depkes.go.id/resources/ download/infoterkin/materi_rakorpo p_2018/Hasil\%20Riskesdas\%20201 8.pdf 
Heenan, D. (2006). Art as therapy: An effective way of promoting positive mental health? Disability and Society, 21(2), 179-191. https://doi.org/10.1080/0968759050 0498143

Hillier, M. (2007). Rebuilding connections: creating opportunities for socially isolated older Australians

Livingston, J. (2012). Self-Stigma And Quality Of Life Among People With Mental Illness Who Receive Compulsory Community Treatment Services. 40(6), 699-714. https://doi.org/10.1002/jcop

Livingston, J. D., \& Boyd, J. E. (2010). Correlates and consequences of internalized stigma for people living with mental illness: A systematic review and meta-analysis. Social Science and Medicine, 71(12), 2150-2161.

https://doi.org/10.1016/j.socscimed. 2010.09.030.

Rowaert, S., Hanssens, F., Audenaert, K., Vandevelde, S., \& Lemmens, G. (2018). A Family Support Group for Family Members of Offenders with a Mental Illness - Part 2: Treatment Protocol. 487-500. https://doi.org/10.1002/anzf.1336

Owaert, S. et al. (2018) 'A Family Support Group for Family Members of Offenders with a Mental Illness Part 2: Treatment Protocol', pp. 487-500. doi: 10.1002/anzf.1336.
Seebohm, P., Ma, B. A., Chaudhary, S., Ma, L. L. B., Ba, M. B., Elkan, R., ... Ma, C. M. B. A. (2013). The contribution of self-help / mutual aid groups to mental well-being. 21, 391-401. https://doi.org/10.1111/hsc.12021

Sudiantara., K dkk, (2015) Pengaruh Self Help Group Therapy Terhadap Peningkatan Kemampuan Merawat diri dan Kualitas Hidup Lansia. http://www.poltekkesdenpasar.ac.id/wpcontent/uploads/2017/12/sudiantara. pdf

Sulistyowati,E.C. Sulistyowati, D., (2019). Pemberdayaan Pasien dengan Pendekatan Self Help Group terhadap Perubahan Mekanisme Koping pada pasien Gangguan Jiwa Skizoprenia di RSJD Dr Arif Z Surakarta. Poltekkes Surakarta, Interes Jurnal Ilmu Kesehatan No1, Vol 8. http://jurnalinterest.com/index.php/i nt/article/view/123/119

Taylor, S. E. (2011). Taylor, S. E. (2011). Social support: A review. In H. S. Friedman (Ed.), The Oxford handbook of health psychology (pp. 192-217). New York, NY: Oxford University Press. /10.1093/oxfordhb/9780195342819. 013.0009. 192-217.

Tew, J., Ramon, S., Slade, M., Bird, V., Melton, J., \& Le Boutillier, C. (2012). Social factors and recovery from mental health difficulties: A review of the evidence. British Journal of Social Work, 42(3), 443- 
460.

https://doi.org/10.1093/bjsw/bcr076

UU Kesehatan no 18 2014. Tentang Kesehatan Jiwa https://ipkindonesia.or.id/media/201 7/12/uu-no-18-th-2014-ttgkesehatan-jiwa.pdf

WHO. (2019). WHO 2019 Mental disorders https://www.who.int/newsroom/fact-sheets/detail/mentaldisorders

Williams, E., Bn, H., Sands, N., Bn, H., \& D, P. (2015). Mental health consumers perceptions of quality of life and mental health care. 299306.

https://doi.org/10.1111/nhs.12189

World Health Organization. (2020). WHO Quality of Life-BREF.

https://www.who.int/toolkits/whoqol/who qol-bref/docs/defaultsource/publishing-policies/whoqolbref/indonesian-whoqol-bref 